\title{
Proceeding
}

7th INSHS International Christmas Sport Scientific Conference, 9-12 December 2012. International Network of Sport and Health

Science. Szombathely, Hungary

\section{Assessment of physical activity level in office employees groups in Albania}

\author{
DHURATA BOZO $1 \square$, GENTI PANO ${ }^{1}$, ROBERT ÇITOZI² \\ ${ }^{1}$ Sport Sciences Research Institute, Sport University of Tirana, Albania. \\ ${ }^{2}$ Faculty of Physical Activity and Recreation, Sport University of Tirana, Albania.
}

\begin{abstract}
Bozo D, Pano G, Çitozi R. Assessment of physical activity level in office employees groups in Albania. J. Hum. Sport Exerc. Vol.8, No. Proc2, pp. S152-S164, 2013. Insufficient PA is very common in office employees and due to this they are at higher risk for metabolic, cardiovascular and many more other health related risk factor diseases. There is a lack of data regarding the PA level of office employees groups in Albania. Thus the aim of this paper was to identify the PA level in typical representative groups of this category. A total of 164 randomly selected office employees, out of which 97 (52 females and 45 males) from one mobile company and 67 (37 females and 30 males) from a bank, participated in this study. An Albanian modified and adapted version of the an International Physical Activity Questionnaire was used to assess some indicators dealing with all kinds of PA jobs, everyday life and leisure and time expenditure on PAs of different intensity. The weekly activity level was measured through time, frequency and intensity, expressed in MET*minute/week. The subjects were classified in 3 main PA categories: HIGH (1500-3000 MET*min), MODERATE (600-1300 MET*min) and LOW (<600 MET*min). The results show that both groups declared an average PA Level classified under the LOW category. The values of the mobile company group was around $950 \mathrm{MET}^{*}$ min with a difference between the genders of $280 \mathrm{MET}^{*} \mathrm{~min}$ (1070 in males and 790 in females); while the bank group revealed lower values, i.e. $890 \mathrm{MET}^{*} \mathrm{~min}$ as average and

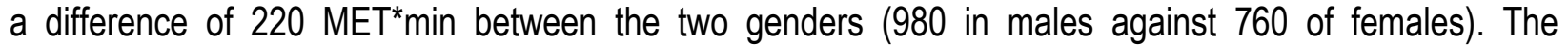
differences between the two groups under investigation can be explained through various factors such as the general PA gender differences, type of sedentary work, type of different work position/role and working spaces. These results may be also a consequence of improper individual activity habits, low information and awareness of health benefits of PA and lack of proper promotion for a healthy and active lifestyle. Key words: SEDENTARITY, OFFICE EMPLOYEES, ALBANIA, PHYSICAL ACTIVITY LEVEL, PA QUESTIONNAIRE.
\end{abstract}

\footnotetext{
Corresponding author. Sport University of Tirana, Sport Science Research Institute, Bul. M. Gjollesha, 1001, Tirana, Albania. E-mail: dhuratabozo@gmail.com

7th INSHS International Christmas Sport Scientific Conference, 9-12 December 2012. International Network of Sport and Health Science. Szombathely, Hungary.

JOURNAL OF HUMAN SPORT \& EXERCISE ISSN 1988-5202

(c) Faculty of Education. University of Alicante

doi:10.4100/jhse.2012.8.Proc2.19
} 


\section{INTRODUCTION}

Modern lifestyles, rapid progress of civilization, development of advanced technologies and unbalanced diet have been proved to influence the overall human health. Insufficient PA on the other side is a particularly important factor whose reduction is found to be at the base of serious conditions such as increase in the body mass, metabolic, cardiovascular and many more other health related risk factor diseases (Thorp et al., 2011).

The office workers, because of the particularity of their work and depending on the occupation position, they perform simple physical activity and make wide and common use of new technologies and devices, shortening the duration of such activities (ref). These categories are therefore are more exposed and tending to a more sedentary life and therefore especially exposed to abovementioned risks. A growing body of evidence shows that sedentary behavior accounts for the majority of occupational, transportation, and discretionary time and is associated with an increased risk of obesity, chronic disease, and mortality (Tudor-Locke et al., 2010; Owen et al., 2010). The increasing prevalence of chronic illnesses such as diabetes, obesity and cardiovascular disease has potentially significant negative effects on workforce participation and productivity in developed countries (Evenson \& Terry, 2009).

A recent review by Thorp et al. (2011) concluded that there is some prospective evidence that supports relationships between sedentary behavior, mortality, and health outcomes. Studies have shown that sedentary time is associated more specifically with increased risk for type II diabetes ( $\mathrm{Hu}, 2003$; Helmerhorst et al., 2009) and mortality (Dunstan et al., 2010). Other studies report no association or suggest reverse causality between sedentary time, obesity, and insulin resistance (Ekelund et al., 2008; Ekelund et al., 2009).

There are virtually no comprehensive studies pertaining to physical activity of office workers in particular, most of research conducted on office employees were focused on determining energy expenditure in subjects with identified health risks (Coopoo et al., 2008; Levine et al., 2005), reduction of job-related musculoskeletal diseases (Blangsted et al., 2008) or their working ability and well-being (Martinez \& Latorre, 2006; Sjögren-Rönkä et al., 2002).

It is commonly believed that nature of work of office employees does not require high physical efforts but there are still only suppositions about it since few data exist supporting that view. It is thus justified to quantitatively assess not only total but as well everyday - low, moderate and vigorous habitual physical activity that will allow for an unbiased and relative appraisal of importance of these independent variables in health promotion and will help in constructing appropriate informative and awareness activities as well as programmed, intentional physical activity for this group of employees (Sjögren-Rönkä et al., 2002).

In the above context, the aim of this study was to assess and evaluate the PA level in typical representative groups of this category through two representative samples, bank officers and mobile company employees. It is important to underline, that there is a lack of data regarding the PA level of office employees groups in Albania. Therefore this is the very first study tackling this issue based in a standardized methodology, data elaboration and interpretation. This research will be gradually extended to other sedentary tending categories in terms of sample size and types such as civil and private administration officers, etc. 


\section{MATERIAL AND METHODS}

\section{Participants}

A total of 164 randomly selected office employees, 97 from one mobile company (52 females and 45 males) and 67 from a bank ( 37 females and 30 males), participated in this study. They were randomly gender and age selected; none from the selected groups refused to fill the questionnaire. The age interval of participants was between 24 - 45 years with different distribution in two groups and among the genders. (see also Table 1 below).

\section{Methodology}

An Albanian modified and adapted version of an International Physical Activity Questionnaire (IPAQ) was used in this study. The questionnaire consists of preliminary personal data (gender, age, education) and 7 main questions addressing a variety of PA jobs, everyday life and leisure and time expenditure on PAs of different intensity.

The PA levels were classified in three groups based on intensity: vigorous, moderate and low level activity such as walking and sitting. Vigorous activities are considered physical activities such as lifting weights, aerobics, fast cycling, etc. More generally these are activities that imply breathing and heart beating much faster and harder than during normal activities. Were classified under the moderate activities, PAs which bring to heart frequency and breathing difficulty more intense than in normal activities; these PAs include carrying light loads, bicycling at low speed and difficulty, fast walking. Quiet walking to perform the everyday duties, getting to work, or any PA which does not bring to any heart or breathing modification or difficulty is considered as low level PA. Sitting is also a component classified under the Low level PAs.

The subjects ware required to report and declare the relative data within the last 7 days preceding the questionnaire filling day.

The body mass index (BMI) for each individual was calculated based on the individual values of body weight and body height. Body height was measured during inspiration with a traditional stadiometer to the nearest $0.1-0.2 \mathrm{~cm}$ and Body Weight was measured with a digital standing scale approximated to the nearest $100 \mathrm{~g}$. The Body Mass Index (BMI) was calculated as the rate between the Body Weight value and Body Surface BW/BS, where BS $=\mathrm{BH} 2$, or $\mathrm{BMI}=\mathrm{BW} / \mathrm{BH} 2$. For the calculation of the Percent Body Fat was used the method according to Deurenberg et al. (1991), confirmed for its reliability also from other authors (Jackson et al., 2002). According to the above, the formula used to calculate the Body Fat Percentage takes into account the current individual BMI value, age and gender (Deurenberg et al., 1991). The formula to predict and assess the adult body fat percentage (BF\%), based on current BMI, age, and gender is the following:

$$
\text { Adult Body Fat } \%=(1.20 \times \mathrm{BMI})+(0.23 \times \text { Age })-(10.8 \times \text { gender })-5.4 \text {;gender coefficient } \mathrm{M}=1, \mathrm{~F}=0 \text {. }
$$

The filling of the questionnaire were performed under the guidance and monitoring of the authors of this paper. The subjects were informed ahead about the purpose, aim and benefits of the study for themselves. Afterwards they were strictly monitored and guided during the filling process; each expert covered a group of 10 persons at a time, assuring thus a high grade of reliability of the collected data.

Table 1 shows a detailed profile of the groups including statistics, age, gender, education and body composition data. 
Table 1. Profile of study groups.

\begin{tabular}{|c|c|c|c|c|c|c|}
\hline Groups & Gende & & $\begin{array}{c}\text { Age } \\
\text { Mean (yr) } \pm \\
\text { SD }\end{array}$ & $\begin{array}{c}\text { Education } \\
\text { Higher } \\
\text { Second }\end{array}$ & $\begin{array}{c}\text { BMI } \\
\text { Mean } \pm \text { SD }\end{array}$ & $\begin{array}{c}\text { BF } \\
\text { calc. BMI }\end{array}$ \\
\hline \multirow{5}{*}{$\begin{array}{l}\text { Mobile } \\
\text { company } \\
\text { employees }\end{array}$} & F & 52 & $33.2 \pm 5.6$ & 42 & $23.9 \pm 3.4$ & 30.9 \\
\hline & $\mathrm{M}$ & 45 & $31.4 \pm 3.9$ & 10 & $27.2 \pm 6.7$ & 23.66 \\
\hline & & & & 33 & & \\
\hline & Tot & 97 & $32.4 \pm 5.2$ & 12 & $25.4 \pm 4.9$ & 27.6 \\
\hline & & & & $\begin{array}{l}75 \\
22\end{array}$ & & \\
\hline \multirow[t]{5}{*}{ Bank officers } & F & 37 & $34.8 \pm 7.2$ & 30 & $24.8 \pm 5.7$ & 32.4 \\
\hline & $\mathrm{M}$ & 30 & $31.6 \pm 8.3$ & $\begin{array}{c}7 \\
25\end{array}$ & $26.7 \pm 2.1$ & 23.5 \\
\hline & Tot & 67 & $33.4 \pm 7.7$ & 5 & $25.7 \pm 4.1$ & 28.4 \\
\hline & & & & $\begin{array}{l}55 \\
12\end{array}$ & & \\
\hline & $\mathbf{F}$ & 89 & $\mathbf{3 3 . 9} \pm 6.2$ & 72 & $24.3 \pm 4.4$ & 31.6 \\
\hline \multirow{3}{*}{$\begin{array}{l}\text { Total of } \\
\text { groups }\end{array}$} & M & 75 & $31.5 \pm 5.7$ & 17 & $27.0 \pm 4.9$ & 23.5 \\
\hline & & 164 & $32.8 \pm 6.2$ & $\begin{array}{l}58 \\
17\end{array}$ & $25.5 \pm 4.6$ & 27.9 \\
\hline & & & & $\begin{array}{c}130 \\
34\end{array}$ & & \\
\hline
\end{tabular}

Data calculation and analysis

The weekly activity level was measured through time, frequency and intensity, by multiplication of time (minutes of each activity level) by intensity coefficient of that given activity: 8 for vigorous, 4 for moderate and 3.3 for the PAs classified under the low level category. Weekly physical activity is expressed in $M E T^{*}$ minute. The overall weekly activity was obtained as the sum of MET*minute value of three level of activities and expressed in $\mathrm{MET}^{*}$ minute/week.

Based on the collected and calculated data, the subjects were classified under 3 the main PA level categories as to the following:

HIGH: three or more days with vigorous activities with a total of at least $1500 \mathrm{MET}{ }^{*} \mathrm{~min} /$ week.

MODERATE: three or more days with vigorous activities, at least 20 min each or $>5$ days of moderate activities at least $30 \mathrm{~min}$ each and totalling at least $600 \mathrm{MET}{ }^{*} \mathrm{~min} / \mathrm{week}$.

LOW; those individuals not classified under the two above categories and who total a value of $<600$ $\mathrm{MET}^{*} \mathrm{~min} /$ week, considered therefore inactive.

Standard statistical methods (Mean and Standard Deviation) were used for the direct measures and calculated parameters. One way variance analysis for the comparison of data between the two groups and genders was applied. The relationships between the variables studied were assessed through the Pearson's correlation coefficient. A $5 \%$ probability level was determined as statistical significance of differences calculated for each parameter. 


\section{RESULTS}

The present study was conducted in two representative groups of office employees of a bank and a mobile telephone company operating in Albania.

Body composition. The results regarding body composition, i.e. height, weight, BMl and BF\% show both groups had an almost normal body mass as a mean and in both genders (bank and mobile company 25.4 and 25.7 respectively) with an insignificant difference between the groups and genders in both. But around $32 \%$ of the bank officers and around $27 \%$ of the MC employees had a higher BMI and consequently a higher $\mathrm{BF} \%$ than the expected normal values, classified as overweight as to the worldwide accepted standards. $3 \%$ of the overweight bank officials and $4.5 \%$ of the MC display even worse values, classified under obese scores (Table 1).

Physical activity level

From the calculations of physical activity and intensity in terms of MET*min/week, the obtained results show that both groups declared an average PA Level classified under the LOW category. The mean values of the mobile company group was around $950 \mathrm{MET}^{*}$ min with a difference between the genders of 280 MET* ${ }^{*}$ in (1070 in males and 790 in females); while the bank group revealed lower mean values, i.e. 890 $\mathrm{MET}^{*} \min$ as average and a difference of $220 \mathrm{MET}^{*}$ min between the two genders (980 in males against 760 of females). The distribution and percentages of bank and mobile company employees classified as to the standard categories of PA level are presented below in Table 2 and Figure 1.

Table 2. The distribution data and percentages of bank and mobile company employees classified as to the standard categories of $P A$ level.

\begin{tabular}{llll}
\hline Group & PA level & Nr of subjects & $\mathbf{0}$ \\
Mobile company & High & 12 & $13 \%$ \\
employees & Moderate & 30 & $31 \%$ \\
MCE & Low & 55 & $56 \%$ \\
& Total partial MC & $\mathbf{9 7}$ & $\mathbf{1 0 0 \%}$ \\
Bank officials & High & 6 & $9 \%$ \\
BO & Moderate & 18 & $27 \%$ \\
& Low & 43 & $64 \%$ \\
& Total partial BO & $\mathbf{6 7}$ & $\mathbf{1 0 0 \%}$ \\
MCE + BO & & $\mathbf{1 8}$ & $\mathbf{1 1 \%}$ \\
& High & $\mathbf{4 8}$ & $\mathbf{2 9} \%$ \\
& Moderate & $\mathbf{9 8}$ & $\mathbf{6 0} \%$ \\
& Low & $\mathbf{1 0 0} \%$ \\
\hline
\end{tabular}




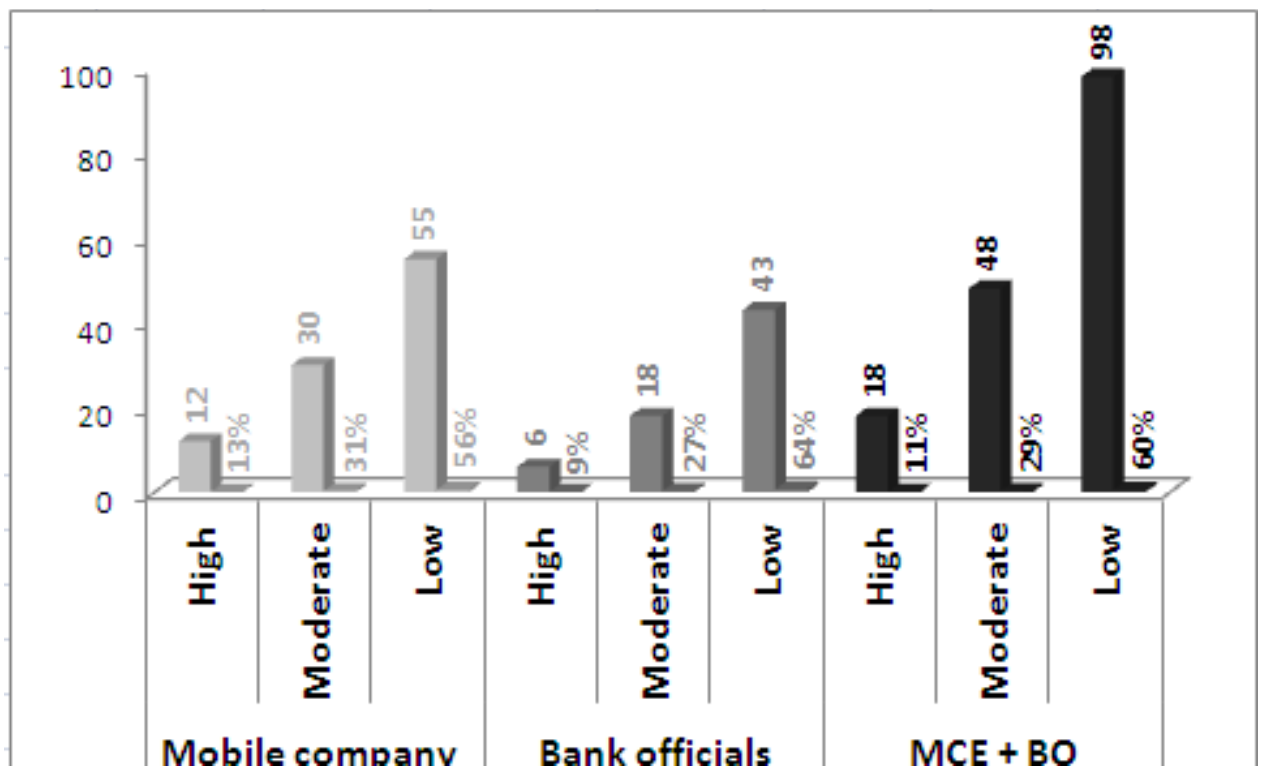

Figure 1. Mobile company and bank employees classified according to standard categories of Physical Activity Level.

The distribution and percentages of bank and mobile company employees classified as to the standard categories of PA level and gender is presented in Table 3 and Figure 2 below.

Table 3. The distribution and percentages of bank and mobile company employees classified as to the standard categories of PA level and gender.

\begin{tabular}{|c|c|c|c|c|c|}
\hline Group & PA level & Subjects F & $\%$ & Subjects M & $\%$ \\
\hline Mobile & High & 4 & $7 \%$ & 8 & $18 \%$ \\
\hline company & Moderate & 17 & $33 \%$ & 13 & $29 \%$ \\
\hline \multirow{2}{*}{$\begin{array}{l}\text { employees } \\
\text { MCE }\end{array}$} & Low & 31 & $60 \%$ & 24 & $53 \%$ \\
\hline & $\begin{array}{l}\text { Total partial } \\
\text { MC }\end{array}$ & 52 & $100 \%$ & 45 & $100 \%$ \\
\hline \multirow{4}{*}{$\begin{array}{l}\text { Bank officials } \\
\text { BO }\end{array}$} & High & 2 & $6 \%$ & 4 & $13 \%$ \\
\hline & Moderate & 12 & $32 \%$ & 6 & $20 \%$ \\
\hline & Low & 23 & $62 \%$ & 20 & $67 \%$ \\
\hline & $\begin{array}{l}\text { Total partial } \\
\text { BO }\end{array}$ & 37 & $100 \%$ & 30 & $100 \%$ \\
\hline \multirow[t]{4}{*}{$\mathrm{MCE}+\mathrm{BO}$} & High & 6 & $6.7 \%$ & 12 & $16 \%$ \\
\hline & Moderate & 29 & $32.6 \%$ & 19 & $25 \%$ \\
\hline & Low & 54 & $60.7 \%$ & 44 & $59 \%$ \\
\hline & $\begin{array}{l}\text { TOTAL } \\
\text { MCE+BO }\end{array}$ & 89 & $100 \%$ & 75 & $100 \%$ \\
\hline
\end{tabular}




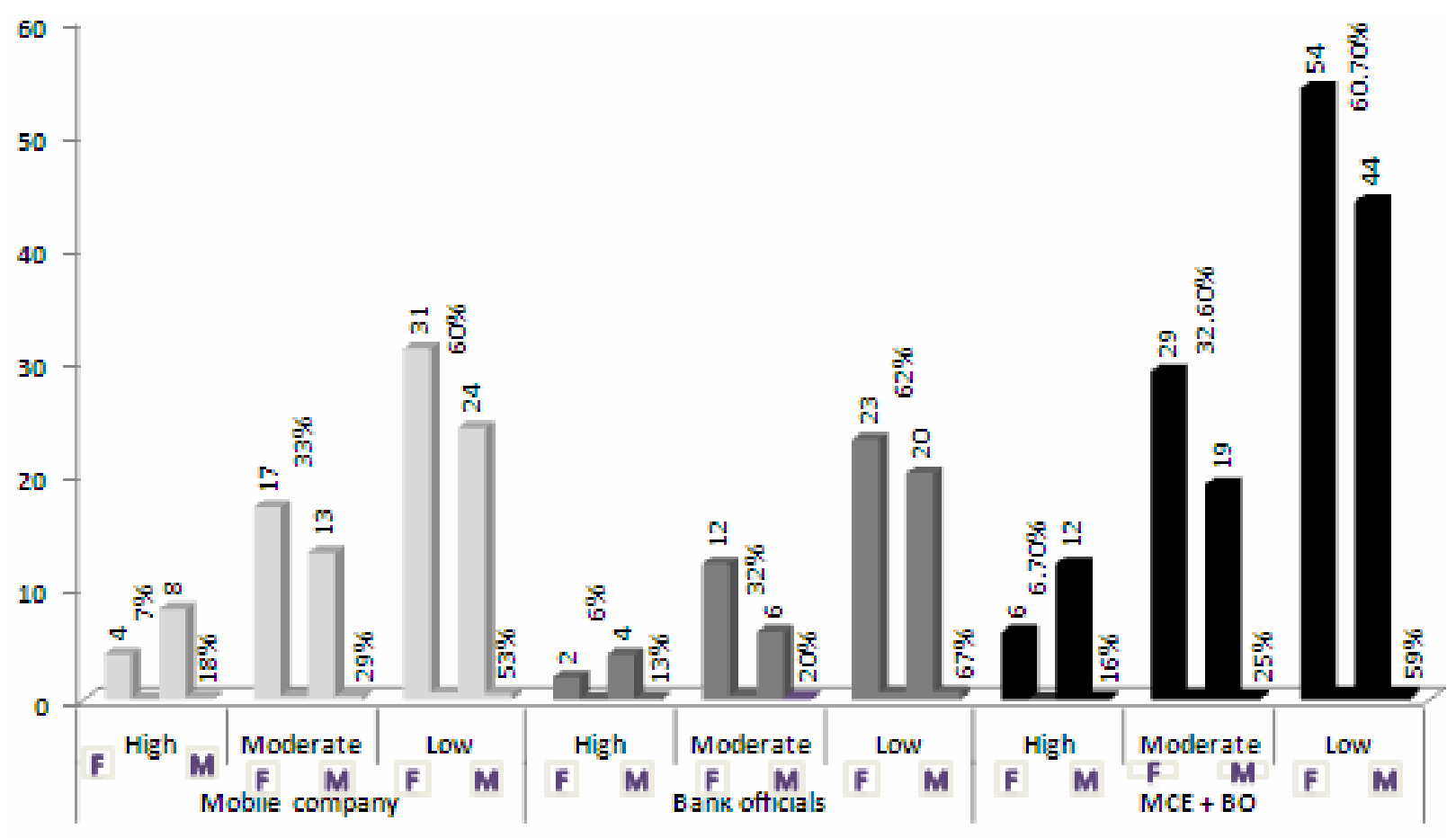

Figure 2. Mobile company and bank employees classified according to standard categories of Physical Activity Level and gender.

The data obtained in both groups were further grouped as to the PA intensity classification, HLPA (High Level PA), MLPA (Moderate Level PA) and LLPA (Low Level PA). However were not observed significant differences between genders in both groups.

The percentages of different kind of activity, in terms of intensity, frequency and time spent for eacj groups and category are presented in Tables 4, 5 and 6.

High level (vigorous) of physical activity

The results show (Table 4) that in both groups around $50 \%$ of the subjects did not practice vigorous activities at all. The mobile company employees practice more frequently high level PA but without exceeding as a mean 60 minutes/week; $2 / 3$ of them practice around 1-2 days/week and not more than 6080 minutes/week. The bank officials show even lower declared values: around $70 \%$ of the subjects who declare to practice vigorous activities, exercise 1-2 days/week and not more than a total of 60 minutes/week. Only $27.5 \%$ of them practice $60-80$ minutes/week. It was also found that bank official dedicated less time during normal days to intense activities, but the differences were found to be non significant ( $6.2 \pm 0.9$ and $5.9 \pm 2.1 \mathrm{~min} / \mathrm{day}$ for MC and bank workers). Only 2 out of 164 subjects ( 1 for each group) declared to practice vigorous activity everyday and for a time exceeding 180minutes/week. 
Table 4. Frequency and weekly time spent for vigorous (high level) activities.

\begin{tabular}{|c|c|c|c|c|c|c|c|}
\hline \multirow{2}{*}{\multicolumn{2}{|c|}{ Variables }} & \multirow{2}{*}{\multicolumn{2}{|c|}{$\begin{array}{c}\text { Mobile company } \\
\text { employees } \\
\mathbf{n}=97\end{array}$}} & \multicolumn{2}{|c|}{$\begin{array}{c}\text { Bank officers } \\
n=67\end{array}$} & \multicolumn{2}{|c|}{$\begin{array}{c}\text { Total of groups } \\
\mathrm{N}=164\end{array}$} \\
\hline & & & & $\mathbf{n}$ & $\%$ & $\mathbf{n}$ & $\%$ \\
\hline & & $\mathbf{n}$ & $\%$ & & & & \\
\hline \multirow{4}{*}{ Frequency } & None & 49 & $50.4 \%$ & 34 & $50.7 \%$ & 83 & $50.6 \%$ \\
\hline & 1-2 days/week & 30 & $30.1 \%$ & 21 & $31.3 \%$ & 51 & $31.1 \%$ \\
\hline & 3-6 days/week & 16 & $16.4 \%$ & 10 & $14.9 \%$ & 26 & $15.8 \%$ \\
\hline & 7 days/week & 2 & $2.1 \%$ & 2 & $3.1 \%$ & 4 & $2.5 \%$ \\
\hline \multirow{3}{*}{$\begin{array}{l}\text { Weekly } \\
\text { time }\end{array}$} & $<60 \mathrm{~min}$ & 33 & $68.7 \%$ & 23 & $69.7 \%$ & 56 & $69.2 \%$ \\
\hline & $60-80 \mathrm{~min}$ & 14 & $29.2 \%$ & 9 & $27.3 \%$ & 23 & $28.4 \%$ \\
\hline & $>180 \mathrm{~min}$ & 1 & $2.1 \%$ & 1 & $3.0 \%$ & 2 & $2.4 \%$ \\
\hline
\end{tabular}

Moderate physical activity

Activities classified under the moderate intensity category were not practiced by $17.5 \%$ and $27 \%$ respectively of MC and Bank workers. Moderate activities performed less than 60 minutes/week were significantly less frequent by MCE than by BO with percentages $12.5 \%$ and $28.6 \%$ respectively. Moderate activities were undertaken more frequently and with higher weekly time expenditure by MC employees (23\% of them where around $34 \%$ exercising more than 180 minutes/week). While bank officers practice less frequently (only $28 \%$ practice 3-6 days/week) and with a lower time spent on those activities (55\% only 60-80 minutes/week). $14.5 \%$ of MC employees exercise 7 days/week, against only $9 \%$ of the Bank Officers. The same significant difference was observed for the maximal time spending in moderate activities between groups: $34 \%$ of MCE and only $16 \%$ of BO spend more than 180 minutes/week on such activities.

Table 5. Frequency and weekly time spent for moderate level activities.

\begin{tabular}{|c|c|c|c|c|}
\hline \multicolumn{2}{|c|}{ Variables } & $\begin{array}{c}\text { Mobile company } \\
\text { employees } \\
\mathbf{n}=97\end{array}$ & $\begin{array}{c}\text { Bank officers } \\
n=67 \\
n\end{array}$ & $\begin{array}{c}\text { Total of } \\
\text { groups } \\
n=164\end{array}$ \\
\hline & & $\begin{array}{l}\mathbf{n} \\
\%\end{array}$ & $\%$ & $\begin{array}{l}\mathbf{n} \\
\%\end{array}$ \\
\hline \multirow[t]{8}{*}{ Frequency } & None & 17 & 18 & 35 \\
\hline & 1-2 days/week & $17.5 \%$ & $26.9 \%$ & $21.3 \%$ \\
\hline & 3-6 days/week & 37 & 24 & 61 \\
\hline & 7 days/week & $38.1 \%$ & $35.8 \%$ & $37.2 \%$ \\
\hline & & 29 & 19 & 48 \\
\hline & & $29.9 \%$ & $28.3 \%$ & $29.7 \%$ \\
\hline & & 14 & 6 & 20 \\
\hline & & $14.5 \%$ & $9 \%$ & $11.8 \%$ \\
\hline \multirow[t]{6}{*}{ Weekly time } & $<60 \mathrm{~min}$ & 10 & 14 & 24 \\
\hline & $60-80 \mathrm{~min}$ & $12.5 \%$ & $28.6 \%$ & $18.3 \%$ \\
\hline & $>180 \mathrm{~min}$ & 43 & 27 & 70 \\
\hline & & $53.7 \%$ & $55.1 \%$ & $53.4 \%$ \\
\hline & & 27 & 8 & 35 \\
\hline & & $33.8 \%$ & $16.3 \%$ & $28.3 \%$ \\
\hline
\end{tabular}


Low level activity: walking

Differently from the results obtained for vigorous and moderate level physical activities, MCEs and BOs declare very similar values for low level activities including walking, in terms of frequency and weekly time spent. The results reports below (Table 6) include data on walking frequency and weekly time spent only.

Walking was not declared as a physical activity by about $10 \%$ of both groups. Likewise the two groups declare similar data on walking frequency $(39 \%, 30 \%$ and $20 \%$ of MCE against $40 \%, 33 \%$ and $17 \%$ of BO for 1-2, 3-6 and 7 days/week activity respectively) but less in terms of weekly time spent on this kind of activity $(17 \%, 46 \%$ and $37 \%$ of MCE against $18 \%, 53 \%$ and $29 \%$ of BO for $<60 \mathrm{~min} / \mathrm{week}, 60-80 \mathrm{~min} /$ week and $>180 \mathrm{~min} /$ week, respectively).

Table 6. Frequency and weekly time spent for low level activities.

\begin{tabular}{|c|c|c|c|c|c|c|c|}
\hline \multicolumn{2}{|c|}{ Variables } & \multicolumn{2}{|c|}{$\begin{array}{c}\text { Mobile company } \\
\text { employees } \\
n=97\end{array}$} & \multicolumn{2}{|c|}{$\begin{array}{c}\text { Bank officers } \\
n=67\end{array}$} & \multicolumn{2}{|c|}{$\begin{array}{c}\text { Total of groups } \\
n=164\end{array}$} \\
\hline & & $\mathrm{n}$ & $\%$ & $\mathrm{n}$ & $\%$ & $\mathrm{n}$ & $\%$ \\
\hline \multirow{4}{*}{ Frequency } & None & 10 & $10.3 \%$ & 7 & $10.4 \%$ & 17 & $10.4 \%$ \\
\hline & 1-2 days/week & 38 & $39.2 \%$ & 27 & $40.3 \%$ & 65 & $39.6 \%$ \\
\hline & 3-6 days/week & 29 & $29.9 \%$ & 22 & $32.8 \%$ & 51 & $31.1 \%$ \\
\hline & 7 days/week & 20 & $20.6 \%$ & 11 & $16.5 \%$ & 31 & $18.9 \%$ \\
\hline \multirow[t]{3}{*}{ Weekly time } & $<60 \mathrm{~min}$ & 15 & $17.2 \%$ & 11 & $18.3 \%$ & 26 & $17.7 \%$ \\
\hline & $60-80 \mathrm{~min}$ & 40 & $46 \%$ & 32 & $53.3 \%$ & 72 & $48.3 \%$ \\
\hline & $>180 \mathrm{~min}$ & 32 & $36.8 \%$ & 17 & $28.4 \%$ & 49 & $35 \%$ \\
\hline
\end{tabular}

The results regarding the sitting declared time, did not reveal significant differences between the groups. The mean value of the weekly overall time spent sitting is around $10.2 \pm 2.7$ hours/day irrespectively of gender as well.

Calculations of the overall weekly activity level, obtained as the sum of MET*minute value of three level of activities and expressed in MET*minute/week, show that both groups have an average PA Level classified under the LOW category. The values of the mobile company group was around 950 MET*min with a difference between the genders of $280 \mathrm{MET}^{*} \min$ (1070 in males and 790 in females); while the bank group revealed lower values, i.e. $890 \mathrm{MET}^{*}$ min as average and a difference of $220 \mathrm{MET}^{*}$ min between the two genders (980 in males against 760 of females). The differences between the two groups under investigation can be explained through various factors such as the general PA gender differences, type of sedentary work, type of different work position/role and working spaces. These results may be also a consequence of improper individual activity habits, low information and awareness of health benefits of PA and lack of proper promotion for a healthy and active lifestyle in the country. 


\section{DISCUSSION AND CONCLUSIONS}

Our study was conducted in two groups of office employees categories which are considered as more tending to a sedentary lifestyle and therefore expected to be less active than other groups of the population. On the other side, these represent selected groups considering their level of education, information, civilization status, awareness and sensibility to health and sport.

The obtained results show that Bank officers and the mobile company employees have similar values for body mass index (mean 25.4 and 25.7 respectively) and therefore similar percentage of body fat (27.6 and $28.4 \%$ respectively). The mean values of $\mathrm{BMI}$ in both groups are in the cutedge between the normal and overweight as to the standards; in fact about $30 \%$ of MCE and $32 \%$ of BO are overweight with BMI over 30 (Katzmarzyk, 2002). Despite the insignificant differences, BOs who display higher value of BMI are in fact less active especially for moderate and low level activities and a higher weekly sitting spent time (10.7 against 9.9 of MCEs). Differences in BMI values between the groups seem positively correlated to the mean ages of the groups, despite these differences are insignificant.

The average time of sitting was almost the same in each group (around 10.2 hours/day) and is almost 4 hours/day higher than that reported for example in Sweden, where the average sitting time at population level is around 6.9 hours/day (Ekelund et al., 2006). This is obviously explainable giving the long traditions of healthy lifestyle and the widely spread health promotion carried out in this and the Scandinavian countries in general.

Low level of physical activity was encountered in about $60 \%$ of the subjects with minimal differences between the two groups. These results are generally concordant with those reported from other studies in European countries. In a similar study in Poland, around $64 \%$ of administration and local office employees declare to practice this kind of PA (Biernat et al., 2010). The prevalence of subjects classified as having low and/or very low physical activity may be a result of improper habits of spending free time, low information and awareness on beneficial effects of physical activity and exercising, insufficient promotion for healthy and active lifestyle or simply lack of time and/or easily accessible facilities for practicing such popular kind of PA. Walking, as a component of low level PA was mostly declared and more in terms of time/week by bank officers. Average time of walking reported for both groups war about $160 \mathrm{~min} / \mathrm{week}$, i.e. $23 \mathrm{~min} /$ day with a significant difference between females and males (32 against 20) which is reflected in the higher percentage of females practicing low level PA (64\% against $56 \%$ of males). The abovementioned values in Albanian groups are lower than the minimal value recommended as limit for PA (at least $30 \mathrm{~min} / \mathrm{day}$ ). It is possible that similar results and tendencies would be found for other eastern and south European countries in way of development.

Moderate level activity was found on average of $29 \%$ of office workers. Although relatively high percentages of subjects exhibiting moderate physical activity, only $11 \%$ of the groups under this study have high level values of physical activity. In a study conducted in analogous groups in Poland (Biernat et al., 2010) a higher percentage $(46 \%)$ of them practice moderate physical activity, and the average intensity/frequency/time values for this kind of activity (MET*min/week) is also higher than in the Albanian groups (2514 MET*min/week). As it has been demonstrated from different studies and institutions (American College of Sport Medicine-ACSM) 150 minutes of moderate physical activity per week with a duration of at least $30 \mathrm{~min} /$ day, is recommended as the minimal threshold for such activity (Craig CL et al., 2003). The results show that only $34 \%$ of MCE and $16 \%$ of BO fulfil this criterion; the majority practice less than 4 days/week with duration of less than $90 \mathrm{~min} /$ week. The results are not satisfactory if compared to 
results for example of the Norway where almost $70 \%$ of the population practice this threshold (Ekelund et al., 2006) while $49 \%$ of the Polish study subjects (Biernat et al., 2010) meet these criteria.

According to ACSM practicing of high intensity activities increases the maximal oxygen uptake and therefore decreasing the risk for heart diseases and mortality (Lee et al., 1995). The results of our study show that more than $50 \%$ of our groups do not practice vigorous activities and the values are very similar between the groups. In fact this is a surprisingly relatively low level (quite satisfactory) for our population in general. The high percentage of those practicing high level of PA show very low frequency $67 \%$ of MCE and $70 \%$ of BO practice only 1-2 days/week) and also a very low weekly time in both $(69 \%$ of MCE and $70 \%$ of BO practice not more than $60 \mathrm{~min} /$ week, i.e. less than $8 \mathrm{~min} /$ day as average). Worth to notice the evident differences between genders in both groups in terms of percentages, frequency of practicing and weekly spent time. $18 \%$ of males against less than $7 \%$ of females of the MCE group against $13 \%$ of males against less than $6 \%$ of females of the $\mathrm{BO}$ group (M:F = 2:1); the average of both groups is $16 \%$ for males and $6.7 \%$ for females. In terms of frequency, $79 \%$ of females practice $1-2$ days/week, while $54 \%$ of males practice 3-6 days/week as an average of both groups.

Summarizing and concluding the Albanian group representatives have a low level of physical activity, lower than in many developed countries but comparable to south-eastern European countries sharing similarities in social, economic contexts, and level of cultural and education development. These results demonstrate for an insufficient public health and health related information and education and ineffectiveness or inappropriateness of programs promoting health and sport. The abovementioned factors summed to the civilization, development of technology and tendency to sedentary behaviour of particular groups, alert for further efforts and more efficient ways to promote good health through movement and sport all over the country and in local special working environments.

\section{REFERENCES}

1. BIERNAT E, TOMASZEWSKI P, MILDE K. Physical activity of office workers. Biol Sport. 2010; 27:289-296.

2. BLANGSTED AK, SØGAARD $K$, HANSEN EA, HANNERZ $H$, SJøGAARD G. One-year randomized controlled trial with different physical-activity programs to reduce musculoskeletal symptoms in the neck and shoulders among office workers. Scand. J Work Environ Health. 2008; 34(1):55-65.

3. CRAIG CL, MARSHALL AL, SJÖSTRÖM M, BAUMAN AE, BOOTH ML, AINSWORTH BE, PRATT M, EKELUND U, YNGVE A, SALLIS JF, OJA P. International Physical Activity Questionnaire: 12Country Reliability and Validity. Med Sci Sports Exerc. 2003; 35(8):1381-1395.

4. COOPOO Y, CONSTANTINOU D, ROTHBERG AD. Energy expenditure in office workers with identified health risks. SAJSM. 2008; 20(2):40-43.

5. CLARK BK, SUGIYAMA T, HEALY GN, SALMON J, DUNSTAN DW, OWEN N. Validity and reliability of measures of television viewing time and other non-occupational sedentary behaviour of adults: a review. Obes Rev. 2009; 10(1):7-16.

6. DEURENBERG P, WESTSTRATE JA, SEIDELL JC. Body mass index as a measure of body fatness: age- and sex-specific prediction formulas. British Journal of Nutrition. 1991; 65(2):105-114.

7. DUNSTAN DW, BARR EL, HEALY GN, SALMON J, SHAW JE, BALKAU B, MAGLIANO DJ, CAMERON AJ, ZIMMET PZ, OWEN N. Television viewing time and mortality: the australian diabetes, obesity and lifestyle study (ausdiab). Circulation. 2010; 121(3):384-391. 
8. EKELUND U, SEPP $H$, BRAGE $S$, BECKER W, JAKES R, HENNINGS M, WAREHAM NJ. Criterion-related validity of the last 7-day, short form of the International Physical Activity Questionnaire in Swedish adults. Public Health Nutr. 2006; 9(2):258-265.

9. EKELUND U, BRAGE S, BESSON H, SHARP S, WAREHAM NJ. Time spent being sedentary and weight gain in healthy adults: reverse or bidirectional causality? American Journal of Clinical Nutrition. 2008; 88(3):612-617.

10. EKELUND U, BRAGE S, GRIFFIN J, WAREHAM NJ. Objectively measured moderate- and vigorous-intensity physical activity but not sedentary time predicts insulin resistance in high-risk individuals. Diabetes Care. 2009; 32(6):1081-1086.

11. EVENSON KR, TERRY JW JR. Assessment of differing definitions of accelerometer nonwear time. Res Q Exerc Sport. 2009; 80(2):355-62.

12. HELMERHORST HJF, WIJNDAELE K, BRAGE S, WAREHAM NJ, EKELUND U. Objectively measured sedentary time may predict insulin resistance independent of moderate- and vigorousintensity physical activity. Diabetes. 2009; 58(8):1776-1779.

13. HU FB. Sedentary lifestyle and risk of obesity and type 2 diabetes. Lipids. 2003; 38(2):103-108.

14. JACKSON AS, STANFORTH PR, GAGNON J, RANKINEN T, LEON AS, RAO DC, SKINNER JS, BOUCHARD C, WILMORE JH. The effect of sex, age and race on estimating percentage body fat from body mass index: the Heritage Family Study. Int J Obes Relat Metab Disord. 2002; 26(6): 789-96.

15. KATZMARZYK PT. The Canadian obesity epidemic: an historical perspective. Obes Res. 2002; 10(7):666-674.

16. LEE IM, HSIEH CC, PAFFENBARGER RS JR. Exercise intensity and longevity in men. The Harvard Alumni Health Study. JAMA. 1995; 273(15):1179-1184.

17. LEVINE JA, LANNINGHAM-FOSTER LM, MCCRADY SK, KRIZAN AC, OLSON LR, KANE PH, JENSEN MD, CLARK MM. Interindividual variation in posture allocation: possible role in human obesity. Science. 2005; 307(5709):584-586.

18. MARTINEZ MC, LATORRE MRDO. Health and work ability among office workers. Rev Saúde Pública. 2006; 40(5):1-7.

19. OWEN N, GHEALY GN, MATTHEWS CE, DUNSTAN DW. Too much sitting: the population health science of sedentary behaviour. Exercise and Sport Sciences Reviews, 2010; 38(3):105-113.

20. RAITAKARI OT, JUONALA M, KÄHÖNEN M, TAITTONEN L, LAITINEN T, MÄKI-TORKKO N, JÄRVISALO MJ, UHARI M, JOKINEN E, RÖNNEMAA T, AKERBLOM HK, VIIKARI JS. Cardiovascular risk factors in childhood and carotid artery intima-media thickness in adulthood: the Cardiovascular Risk in Young Finns Study. JAMA. 2003; 290(17):2277-2283.

21. ROSENBERG DE, BULL FC, MARSHALL AL, SALLIS JF, BAUMAN AE. Assessment of sedentary behavior with the International Physical Activity Questionnaire. J Phys Act Health. 2008; 5(Suppl 1):S30-44.

22. SJÖGREN-RÖNKÄ T, OJANEN MT, LESKINEN EK, MUSTALAMPI ST, MÄLKIÄ EA. Physical and psychosocial prerequisites of functioning in relation to work ability and general subjective wellbeing among office workers. Scand J Work Environ Health. 2002; 28(3):184-190.

23. SMITH MJ, CONWAY FT, KARSH BT. Occupational stress in human computer interaction. Ind Health. 1999; 37(2):157-173.

24. THORP A, OWEN N, NEUHAUS, M, DUNSTAN D W. Sedentary behaviors and subsequent health outcomes in adults: a systematic review of longitudinal studies, 1996-2011. American Journal of Preventive Medicine. 2011; 41(2):207-215. 
25. TUDOR-LOCKE C, JOHNSON WD, KATZMARZYK PT. Frequently reported activities by intensity for U.S. adults: the American time use survey. American Journal of Preventive Medicine. 2010; 39(4):e13-e20. 